\title{
Prediction of the swelling capacity of salt-insensitive superabsorbent polymers in concrete by rheological measurements
}

\author{
Oliver Mazanec ${ }^{1, *}$, Alessander Assmann², and Diana Eissmann ${ }^{3}$ \\ ${ }^{1}$ Regional Business Segment Management Admixture Systems Europe, BASF Construction Solution GmbH, Trostberg, Germany \\ ${ }^{2}$ Application Technology - Construction Additives, BASF Construction Solution GmbH, Trostberg, Germany \\ ${ }^{3}$ Production, Chemist, BASF Construction Solution GmbH, Trostberg, Germany
}

\begin{abstract}
A study on the macroscopic viscosity of a flowable, fine-grained high-strength mortar was conducted in order to estimate the swelling capacity of two salt-insensitive superabsorbent polymers (SAPs). In doing so, rotational rheometer measurements of the mortar modified with dry pre-mixed SAP were performed at several water-to-cement ratios (W/C), i.e. in the range 0.32 to 0.40 . The swelling capacity of each SAP was estimated by correlating the fitted macroscopic viscosity vs. solid particle fraction curve with the curve of the plain mortar without addition of SAP, produced at the same W/C. The swelling capacities were found to yield $28 \mathrm{~g}$ pore water per g dry SAP $(\mathrm{g} / \mathrm{g})$ and $35 \mathrm{~g} / \mathrm{g}$, respectively. In addition to this new approach, two more practical relevant test methods were evaluated with respect to swelling capacity: first, comparative mortar spread tests, which were based on the use of the same fresh mortars but with less amount of superplasticizer, and second, tea bag tests with plain SAP immersed in an artificial pore solution. Only minor differences were found for the estimated swelling capacities. Hence the conclusion may be drawn that all three test methods are suitable for determining the swelling capacity of SAP in a cementitious environment.
\end{abstract}

Key words: macroscopic viscosity, salt-insensitive superabsorbent polymers, swelling capacity, tea bag test.

\section{Introduction}

The main goal of using SAP as construction additive to concrete and cement-based dry mortars, is in the ability to gain control on water balance and functional pore design. So far, the application of SAP for the purpose of internal curing and durability enhancement of concrete has been the main focus [1]. As well as the amount of entrained water and pores, the spatial distribution of the already saturated cavities dictates the success of this technology [2]. Whereas size and shape of the dry particles are adjustable within production related limits [3], a test method for the reliable prediction of the swelling capacity of SAP in a cementitious environment is required. The swelling capacity is defined as the ratio of absorbed fluid to the mass of dry SAP and determines the final size and distribution of the already saturated SAP pores.

The absorption kinetics of SAP are mainly driven by osmosis. The ion concentration in the swelling medium and the molecular structure of the SAP itself, e.g. cross-linking density and anionicity, have the highest influence on the swelling capacity [4], [5]. Furthermore, the particle size of SAP appears to influence both the swelling capacity, and the speed of absorption [6]. In [6], Fick's second law of diffusion was applied to describe the swelling process.

Most investigations on the swelling capacity of SAPs refer to gravimetric, and optical investigations of bulk SAP material immersed in water, or an artificial pore solution, refer to [7] for a list. Characterization of swelling capacity under real conditions is much more difficult. In other words, real conditions mean changing ion concentration with hydration time and mechanical stress applied during mixing or caused by the net weight of the fresh mortar after being placed in the mould.

A commonly used approach is to estimate the swelling capacity by adjusting the amount of added water required, whilst obtaining the same slump flow of a reference mixture without SAP addition. A refinement of this approach was presented by Mönnig [8]. He compared the mortar spread as a function of additional mixing time. The test method is referred to as comparative mortar spread test which is described in Chap. 3.2.

Trtik et al. used neutron tomography to visualize the water uptake of SAP in fresh mortar [9]. However, only a very large sized SAP particle of $\sim 1 \mathrm{~mm}$ in dry state could be observed. A comparable experiment for estimating the water uptake of SAP is high resolution 
NMR relaxation, which was conducted by Nestle et al. [10].

Another method for estimating the water absorption of internal curing agents is suggested by Johansen et al. [11] and was applied to wooden pulp fibres. The absorption capacity was derived from the difference in $\mathrm{W} / \mathrm{C}$ of a reference cement paste, and a cement paste with internal curing. Both show the same rate of heat evolution under isothermal conditions, despite the difference in total W/C. However, this approach conflicts with the fact that, an internally cured cement paste reaches a higher degree of hydration compared to a reference with lower W/C and, consequently, develops a higher heat of hydration.

The volume fraction of spherical SAP pores, derived from the respective area fraction of the voids by evaluating polished cross-sections of hardened mortar samples, can also be used to determine the swelling capacity of SAP. First results on this approach were published by Jensen [12].

In this paper, a new test method for the estimation of the swelling capacity of SAP is presented and compared to existing methods.

It is based on elaborative rheometer measurements and refers to the correlation of the fitted macroscopic viscosity vs. solid particle fraction curve of a flowable, fine-grained high strength mortar.

\section{Experimental investigation}

\subsection{Materials}

Two salt-insensitive SAP samples based on acrylamide were used for the different test series (SAP A and SAP B). The polymers contain acrylamide, anionic monomers and crosslinker. SAP B has a higher relative density of anionic groups than SAP A, both samples have an irregular particle shape.

The cement selected for the rheological investigations was Ordinary Portland Cement (CEM I 52.5N from Heidelberg Cement). A reference mortar was prepared from $900 \mathrm{~g} \mathrm{OPC}$ and $1350 \mathrm{~g} \mathrm{CEN}$ standard sand. The $\mathrm{W} / \mathrm{C}$ was 0.35 . The reference mortar mixture contained 54 vol.- $\%$ paste (cement and water) and 46 vol.- $\%$ sand. The solid volume fraction $\phi$ was 0.47 .

To disperse the cement particles, the mixtures were prepared with a powdered polycarboxylate ether superplasticizer (PCE) from BASF Construction Solutions GmbH (Melflux AP 101 F), and its dosage rate is expressed in percentage by mass of cement.

\subsection{Methods}

Test methods for the characterization of superabsorbent polymers are standardized by EDANA, an association of the nonwoven industry. A standard test for the absorption capacity is the so-called tea bag method [13]. A known amount of SAP is placed in a sealed tea bag and put in a test solution. After the swelling time, the tea bag is removed, hung up to remove excess liquid and then weighed. The result is the absorption capacity [4]. In order to study the absorption kinetics as a function of time, the swelling time was varied from 2 to 240 minutes. As the test solution, a synthetic cement pore fluid with the following composition ( $\mathrm{mmol} / \mathrm{l})$ was used in order to simulate test conditions of a real cementitious system: $[\mathrm{Na}+]=98.5,[\mathrm{~K}+]=181.6$, $[\mathrm{SO} 42-]=86.2,[\mathrm{Ca} 2+]=10.0$ with $\mathrm{pH}=13.1$.

The comparative mortar spread tests were performed following the method defined in reference [8]. The mortars were prepared by mixing with a Rilem pan-type mixer. In doing so, the dry pre-mixed blend of $1350 \mathrm{~g}$ sand, $900 \mathrm{~g}$ cement, $0.45 \mathrm{~g} \mathrm{PCE}$ and $2.0 \mathrm{~g} \mathrm{SAP}$ A or $1.5 \mathrm{~g}$ SAP B, was added to the mixing bowl already containing the mixing water. In the case of plain reference mixtures without SAP, the amounts of mixing water were $311 \mathrm{~g}, 315 \mathrm{~g}$ and $319 \mathrm{~g}$. In case of SAP modified mortars, $371 \mathrm{~g}$ of water were added. After 60 seconds of mixing, the bowl was scraped to ensure homogeneity and mixing was continued for another 120 seconds. The mortar spread was measured on a shock table (15 shocks), 4 minutes after first water contact and subsequently, in steps of 7 minutes, up to an age of 67 minutes. Between each spread measurement the mortar was mixed again for 2 minutes to break up agglomerates.

For the rheological investigations the mortar was mixed according to DIN EN 196, using a Rilem pantype mixer. After mixing, the mortar was poured into a Hägermann cone which was placed on a glass plate. The superplasticizer dosage was chosen to yield a flow spread of $280 \pm 10 \mathrm{~mm}$ five minutes after water addition. To achieve the target flow spread, a superplasticizer dosage of $0.125 \%$ by weight of cement was required.

The rheological measurements for yield stress and viscosity were performed $10 \mathrm{~min}$ after water addition using a rotational rheometer (Rheotest $\mathrm{RN} 4$ ) equipped with a vane geometry with a radius of $20 \mathrm{~mm}$. The cup was filled with the mortar, and before commencing the measurements, each mortar was remixed for $10 \mathrm{~s}$ to break up agglomerates, enabling the subsequent observation of structure formation. Thereafter, an increasing shear rate ramp up to $100 \mathrm{~s}^{-1}$ was applied followed by a decreasing shear rate ramp. Only the decreasing ramps are shown in the following.

To determine the rheological properties of the mortars, the solid volume fraction $\phi$ of the plain mortar, without addition of SAP, was varied in steps from 0.40 to 0.52 . The packing density remained unchanged since the relative proportion of the materials was kept constant.

\section{Results and discussion}

\subsection{Absorption kinetics observed by standard tea bag method}

Figure 1 illustrates the amount of synthetic cement pore fluid which is absorbed by $1 \mathrm{~g}$ SAP A and SAP B, as a function of the swelling time. The water 
absorption immediately starts after the tea bag is put in the test solution. Approximately $90 \%$ of the total absorption capacity is reached after 10 minutes swelling time. No loss in the absorption capacity is observed over time, i.e. at least for two hours, indicating that both SAP are salt-insensitive. Saltinsensitive means that there is no break-down in water retention of SAP exposed to cement pore fluid over time. The final swelling capacities measured after 240 minutes are $28 \mathrm{~g}$ pore fluid per g dry SAP A $(\mathrm{g} / \mathrm{g})$, and $35 \mathrm{~g} / \mathrm{g}$ for SAP B. SAP B shows higher absorption rates compared to SAP $A$, which is due to the higher anionic charge density of SAP B.

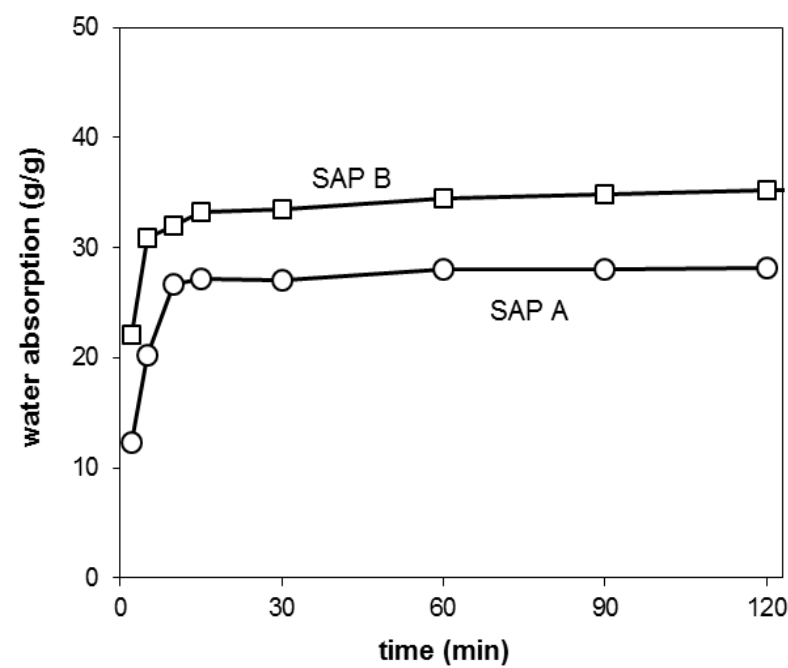

Fig. 1. Absorptivity of the SAP samples in synthetic cement pore fluid.

\subsection{Swelling capacity of SAP estimated by comparative mortar spread tests}

Figure 2 demonstrates the measured mortar spread as a function of the age of the mortar. The dotted lines represent the linear regressions of the test results. For the estimation of the swelling capacity, the reference line which is the closest to the line of the SAP modified mortar is the most suitable one. In case of SAP A modified mortar (left diagram) it is the reference mortar produced with $315 \mathrm{~g}$ water.

In the case of the SAP B modified mortar (bottom diagram) interpolation leads to a hypothetical reference mortar produced with approximately $314 \mathrm{~g}$ water. It is expected that the difference in the total water content, i.e. $56 \mathrm{~g}$ water and $57 \mathrm{~g}$ water, was absorbed by the added SAP, i.e. $2.0 \mathrm{~g}$ SAP A and $1.5 \mathrm{~g}$ SAP B, respectively. This consideration, which includes that water stored in SAP, does not contribute to spread formation, leading to the swelling capacity of SAP, i.e. $28 \mathrm{~g} / \mathrm{g}$ for SAP A and approximately $38 \mathrm{~g} / \mathrm{g}$ for SAP B.

In the case of SAP B, the comparative mortar spread tests led to a swelling capacity which is about $8 \%$ higher compared to the results of the tea bag method.
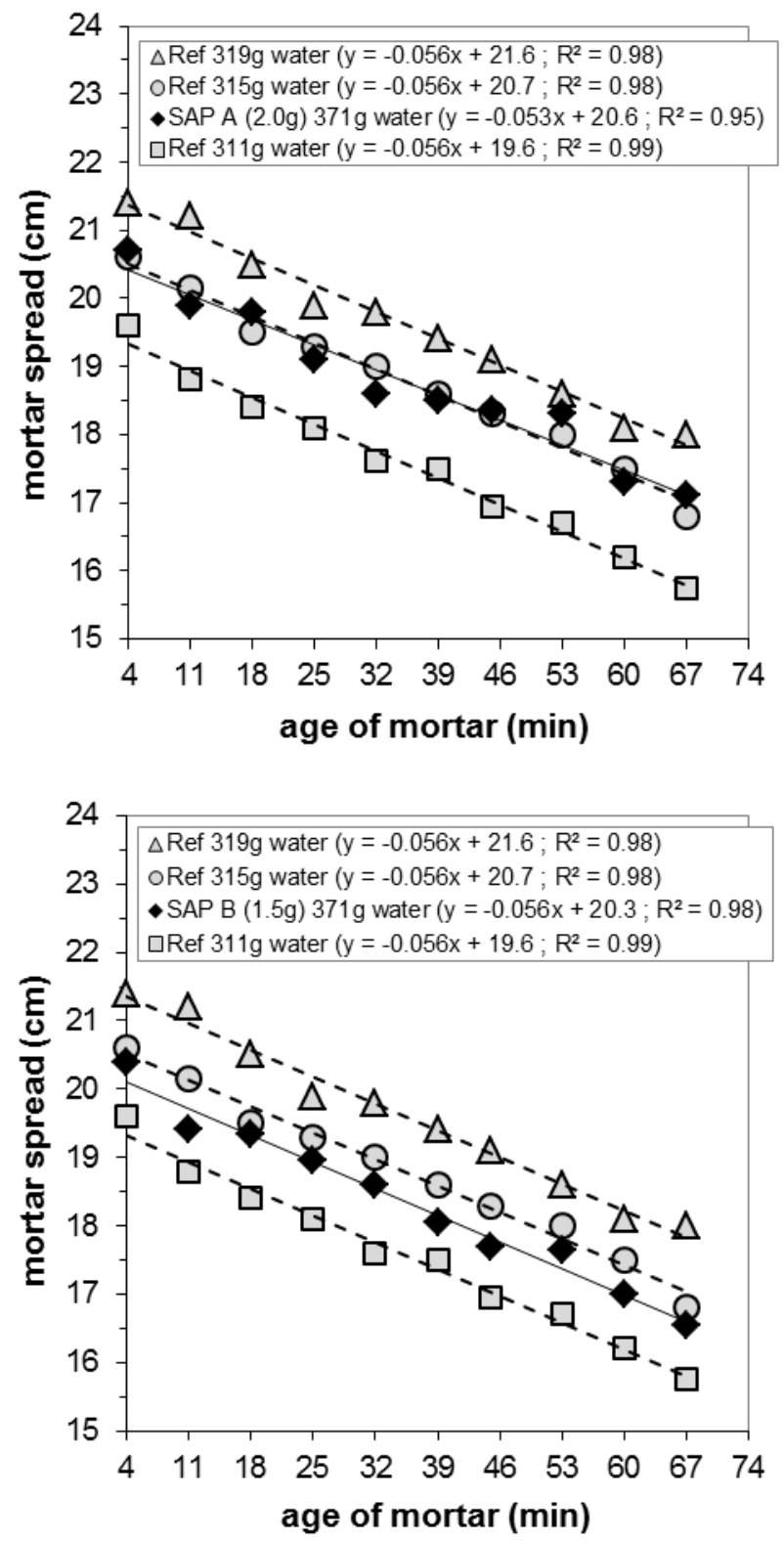

Fig. 2. Mortar spread of SAP A (top) and SAP B (bottom) modified mortar as a function of age compared to curves of plain reference mortars with variable water content. Linear regression of the results is represented by the dotted lines.

\subsection{Swelling capacity of SAP estimated by apparent shear viscosity measurements}

The rheological behaviour of a material is described by its yield stress and its viscosity. The apparent viscosity as a function of the shear rate at different superplasticizer dosages is shown in Figure 3. For the cement mortar a typical shear thinning behaviour (i.e. apparent viscosity is decreasing with shear rate) could be observed. It is known that colloidal attractive interactions between cement particles are the origin of the yield stress of cement mortars, and that the competition between colloidal interactions and viscous dissipation is the origin of the shear thinning behaviour at low shear rates [14]. By increasing the superplasticizer dosage, the shear thinning behaviour is 
less pronounced. On one hand, this can be attributed to the PCE that adsorbs onto the surface of the cement particles and, on the other hand, to steric/electrostatic repulsion effects; the PCE is able to decrease the attractive colloidal interactions. The yield stress of the system decreases along with its contribution to apparent viscosity at low shear rates.

The flow curves for the cement mortar show a plateau in viscosity at a shear rate of $30 \mathrm{~s}^{-1}$. At this shear rate, viscous forces dominate the macroscopic behaviour of the system, i.e. the mortars behave like Newtonian fluids, which means that their viscosities tend towards a constant value [15]. In this case, the contribution of the viscous forces to the macroscopic stress is proportional to the shear rate. They are at the origin of the value of plastic viscosity $\mu p l$, which captures the magnitude of hydrodynamic dissipation.

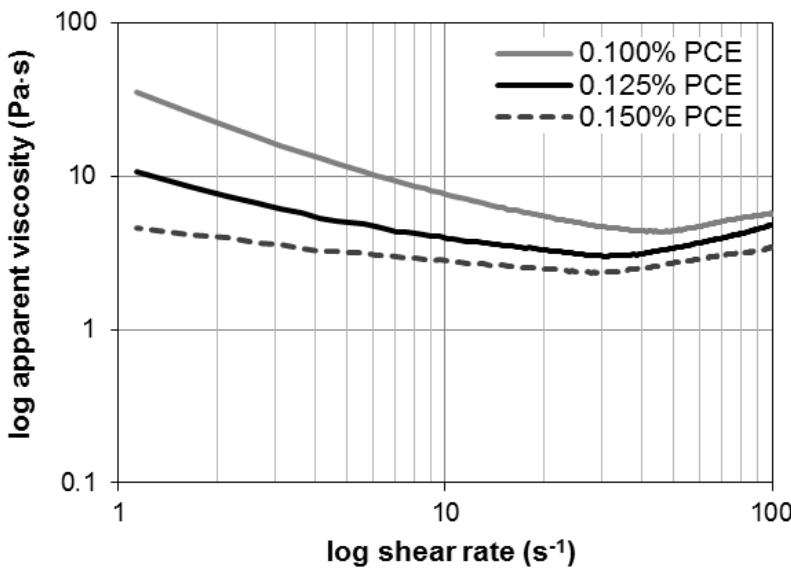

Fig. 3. Apparent viscosity vs. shear rate for different superplasticizer dosages.

In Figure 4 (top diagram) the apparent viscosity as a function of shear rate for various dosages of SAP A is shown. Due to the addition of SAP A the apparent viscosity increases, but a similar shear thinning behaviour to the plain mortar could be observed. The same behaviour was measured by decreasing the W/C ratio from 0.35 to 0.32 at constant $\mathrm{PCE}$ dosage of $0.125 \%$ cf. Figure 4 (bottom diagram).

The effect of SAP dosage on the apparent viscosity at $30 \mathrm{~s}^{-1}$ is shown in Figure 5 (top diagram).

SAP B which has the lowest crosslinking density, showed the greatest effect on the apparent viscosity. This correlates well with the results shown.
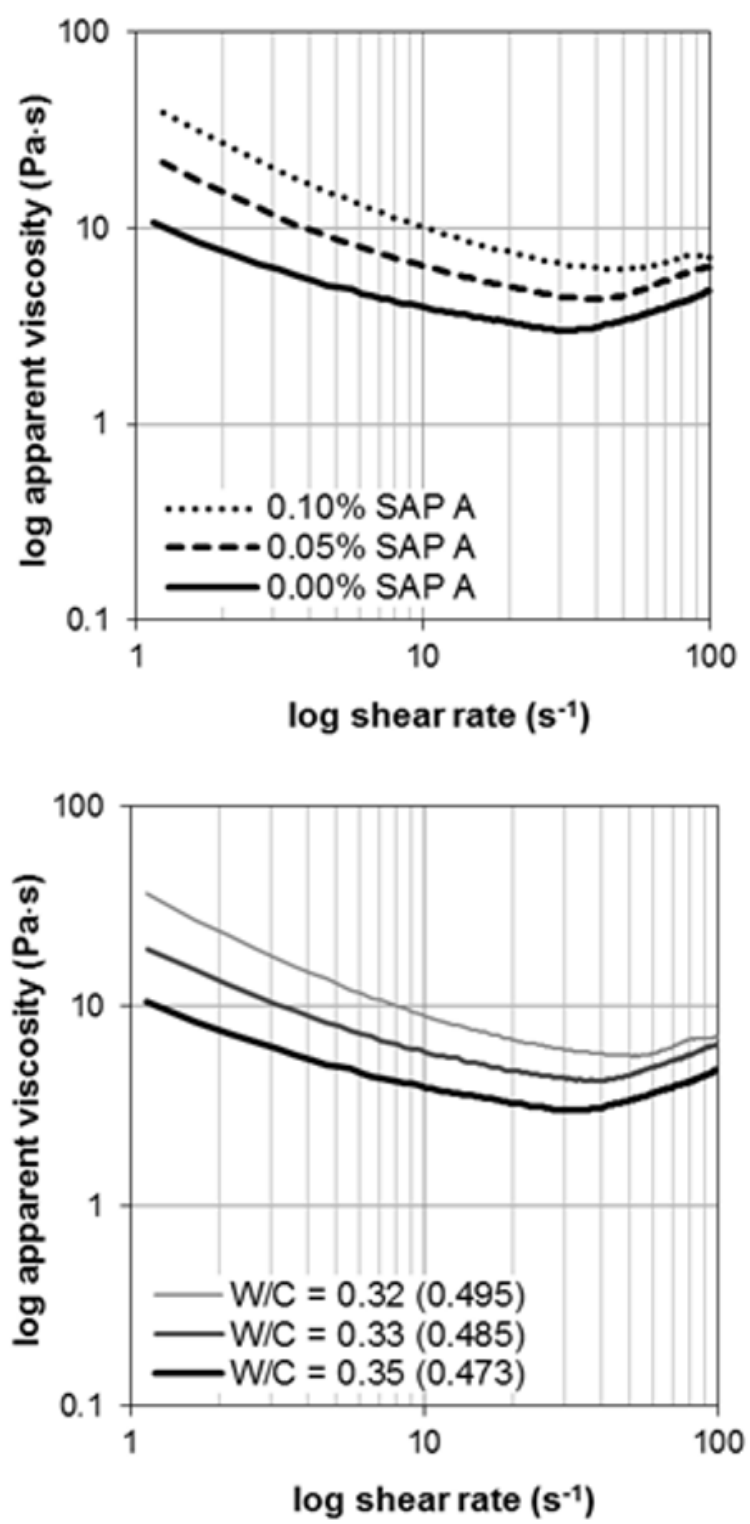

Fig. 4. Apparent viscosity as a function of shear rate of cement mortar at constant $\mathrm{W} / \mathrm{C}$ of 0.35 and variable dosage of SAP A (top) and at different $\mathrm{W} / \mathrm{C}$ ratios and solid volume fractions $\phi$, respectively (bottom).

Due to the higher water absorption capacity of SAP B, the amount of free water in the cement mortar is more reduced compared to SAP A. The reduction of the free water results in an increase of the solid volume fraction. 

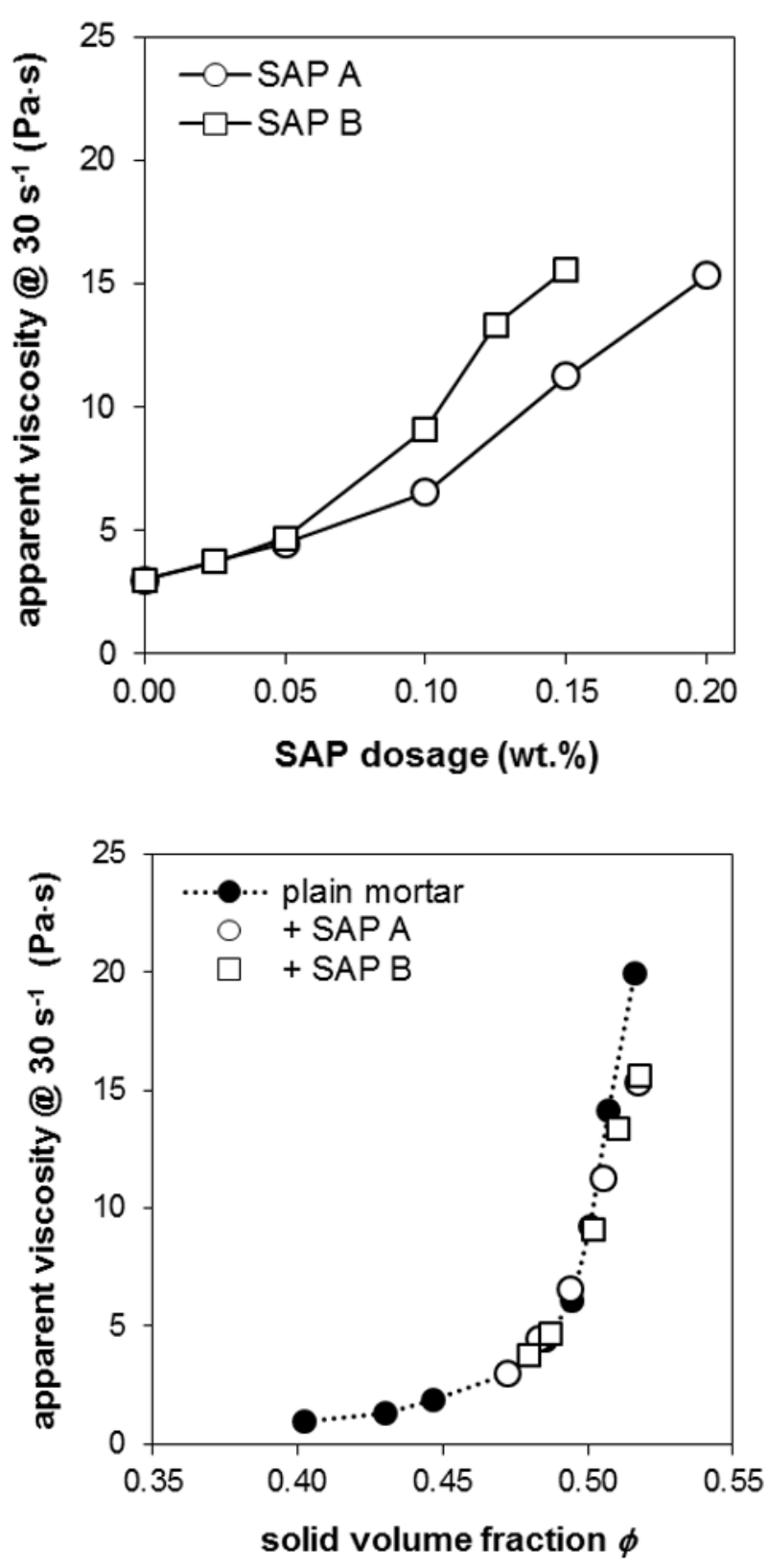

Fig. 5. Effect of SAP dosage on apparent viscosity for cement mortar with a constant solid volume fraction $\phi$ of 0.47 (top) and apparent viscosity vs. solid volume fraction for the plain mortar and mortars with different SAP dosages (bottom).

Recent studies suggest that the viscosity increases by increasing the solid volume fraction $[14,16]$. To characterize the swelling and absorption capacity from the two SAPs, the viscosity has been plotted as a function of the solid volume fraction for the plain mortar, see dotted baseline in Fig. (bottom). It can be noted that the apparent viscosity of the plain mortar increased significantly by decreasing the water content of the mixture. In the next step, it was calculated according to the following equation, how much water is stored by the SAP to fit well with the baseline. It was found that SAP A absorbed $28 \mathrm{~g} / \mathrm{g}$ and SAP B absorbed $38 \mathrm{~g} / \mathrm{g}$.

$$
\phi=\frac{\phi_{\text {solid }}}{\left(\phi_{\text {solid }}+\left(\phi_{\text {water }}-\phi_{\text {water in SAP }}\right)\right)}
$$

here $\phi$ is the volume solid fraction, $\phi$ solid is the volume of solids in the mixture and $\phi$ water is the water content of the mixture.

With this approach it is possible to calculate an estimated swelling capacity of SAP in flowable cement mortars, as well as determining the necessary amount of extra water to compensate an increase in viscosity caused by addition of SAP.

\section{Summary and conclusion}

A study on macroscopic viscosity of a flowable, finegrained high-strength mortar was conducted in order to provide a new approach for the estimation of the swelling capacity of SAP in cementitious mortar systems. This new approach is based on rotational rheometer measurements. The swelling capacity is obtained from the correlation of the fitted macroscopic viscosity vs. solid particle fraction curve of an SAP modified fresh mortar, with the curve of a plain reference mortar produced at different W/C. It can be concluded that the rheological properties of a flowable cement mortar modified with SAP are solely influenced by the water uptake of SAP, and not by any interparticle actions. From the comparison of the estimated swelling capacities of two SAP samples with results from standard tea bag tests, on the one hand and comparative mortar spread test on the other, the following conclusion may be drawn: All three test methods lead to quite similar results. In the case of sample SAP A all three test methods resulted in an estimated swelling capacity of $28 \mathrm{~g} / \mathrm{g}$. In case of sample SAP B the tea bag method led to $35 \mathrm{~g} / \mathrm{g}$. whereas the comparative mortar spread tests, and the rheometer measurements led to a value of $38 \mathrm{~g} / \mathrm{g}$. Since the deviation is less than $10 \%$, and both the comparative mortar spread tests and the rheometer measurements are much more time consuming, the tea bag method (applied in synthetic cement pore fluid) is still recommended as a rapid test for the estimation of the swelling capacity of SAP.

\section{References}

[1] V. Mechtcherine, et al.: "Effect of internal curing by using superabsorbent polymers (SAP) on autogenous shrinkage and other properties of a high-performance fine-grained concrete: results of a RILEM round robin test", Materials and Structures 47 (3), 2014, pp. 541-562

[2] A. Assmann: "Physical properties of concrete modified with superabsorbent polymers", Stuttgart, University of Stuttgart, Department of Construction Materials, Ph.D. thesis, 2013 
[3] F.L. Buchholtz \& A.T. Graham (eds.): "Modern superabsorbent polymer technology“, New York, Wiley-VCH, 1998

[4] S. Friedrich: "Superabsorbent polymers (SAP)", chapter 3 in [7]

[5] C. Schröfl, V. Mechtcherine, M. Gorges: "Relation between the molecular structure and the efficiency of superabsorbent polymers (SAP) as concrete admixtures to mitigate autogenous shrinkage", Cement and Concrete Research 42 (6), 2012, pp. 865-873

[6] L.P. Esteves: "Internal curing in cement-based materials", Aveiro, Universidade de Aveiro, Ph.D. thesis, 2009

[7] V. Mechtcherine, H. W. Reinhardt (eds.): "Application of superabsorbent polymers in concrete construction. State-of-the-art report of the RILEM TC 225-SAP”, Springer, Heidelberg/Germany, 2012, ISBN 978-94-0072732-8

[8] S. Mönnig: "Superabsorbing additions in concrete - applications, modelling and comparison of different internal water sources", Stuttgart, University of Stuttgart, Department of Construction Materials, Ph.D. thesis, 2009

[9] P. Trtik, et al.: Neutron tomography measurements of water release from superabsorbent polymers in cement paste, in: W. Brameshuber (ed.): "Additions improving properties of concrete", Bagneux, RILEM Publications, 2010 (RILEM Proceedings; 77), pp. 175-185

[10] N. Nestle, et al.: "Water balance \& pore structure development in cementitious materials in internal curing with modified superabsorbent polymer studied by NMR", Microporous and Mesoporous Materials 125 (1-2), 2009, pp. 51-57

[11] N.A. Johansen, et al.: "New method for determination of absorption capacity of internal curing agents", Cement and Concrete Research 39 (1), 2009, pp. 65-68

[12] O.M. Jensen: "Autogenous phenomena in cementbased materials", Aalborg University, Department of Building Technology and Structural Engineering, 2005, ISBN 87-91606-00-4

[13] EDANA - Europoean Disposals and Nonwovens Association: "Recommended test method - free swell capacity", ERT 420.2-02, 2002

[14] N. Roussel, A. Lemaitre, R.J. Flatt, P. Coussot: "Steady state flow of cement suspensions: A micromechanical state of the art", Cement and Concrete Research 40 (1), 2010, pp. 77-84

[15] J. Hot, N. Roussel: "Influence of adsorbing polymers on the macroscopic viscosity of concentrated cement pastes", in: Proceedings of the Tenth International Conference on Superplasticizer and other Chemical Admixtures in Concrete, Prague, 2012
[16]L. Struble, G.K. Sun: "Viscosity of Portland cement pastes as a function of concentration", Advanced Cement Based Materials 2, 1995, pp. 62-69 